\title{
Epigenetics and Familial Mediterranean fever
}

\author{
Randa S. Lotfy ${ }^{1}$, , Ola SM. Ali ${ }^{2}$, Waheba A. Zarouk ${ }^{1}$, Hala T. El-Bassyouni ${ }^{3}$, Ghada M. Shehata ${ }^{1}$. \\ ${ }^{1}$ Department of Molecular Genetics and Enzymology, National Research Centre, 12622, Giza, Egypt. \\ ${ }^{2}$ Department of Biochemistry, Faculty of Pharmacy (Girls), Al-Azhar University, 11651, Cairo, Egypt. \\ ${ }^{3}$ Department of Clinical Genetics, National Research Centre, 12622, Giza, Egypt. \\ *Correspondence e-mail, randagad83@yahoo.com.
}

Article history: Received 2021-02-14

Revised 2021-03-08

Accepted 2021-03-30

\begin{abstract}
Throughout the last 20 years, the concept of auto-inflammation is developed, culminating with the finding of how gene mutations of Mediterranean Fever (MEFV) seemed to be causally linked to Familial Mediterranean fever (FMF). The autoinflammatory illnesses presently constitute a wide variety of disorders that have mutual signs of frequent fever, the incidence of hyper-reactive immune cells of hereditary origin, and indicators of inflammation that may occur systemically or specific to an organ with no autoimmunity specific infection. The key causes of the unregulated inflammation are the myeloid innate immune cells which mainly induced production of excessive inflammatory cytokines as IL-1 $\beta$ and IL-18. Deficiencies through various signalling mechanisms regulating innate immune response, especially a single and even multiple inflammasomes hyperreactivity, remain the essence of pathological autoinflammatory phenotype. While FMF would be a monogenic autoinflammatory syndrome, it is genetically complicated and affected by environmental influences. Lately, epigenetic dysregulation has appeared to be a further cause of pathogenesis. Throughout this survey, we are addressing the epigenetic involvement pathways within (FMF).
\end{abstract}

Keywords: Autoinflammatory Diseases; Epigenetics; DNA Methylation; Familial Mediterranean Fever; Gene Expression; Microbiota

\section{INTRODUCTION}

Autoinflammatory disorders are a rising category of weakening and prolonged disorders with clear inflammation, which is sometimes systemic and appears through frequent fever periods. Hyperreactive innate immune cells are considered significant contributors to the pathogenesis of such illnesses. Furthermore, patients with an autoinflammatory illness show in their plasma high standards of the inflammatory cytokines and acute-stage proteins. Initially, the idiom autoinflammation has been used to characterize the existence of clearly uncontrolled inflammation periods within the lack of self-reactive $\mathrm{T}$ cells and/or elevated levels of auto-antibodies, and also without every observable infectious factor ${ }^{1}$. Several autoinflammatory syndromes show systemically and/or organ-specific inflammatory characteristics like frequent cyclic fever, arthritis, serositis, and/or dermal inflammation, innate immune cells stimulation and excessive production of IL-1 $\beta$, especially monocytes ${ }^{2}$. Though at first the autoinflammatory idiom diseases just implemented on these typical inborn monogenic cyclic fever syndromes, like cryopyrin-associated periodic syndromes (CAPS) as well as FMF, this listing is extended yet to be an arising technologies implementation result, like following descent series, and includes a growing amount of recently characterized monogenic defects resulted from inflammation-associated genes mutation. The ample proof is that epigenetic dysregulation takes part in these diseases' pathogenesis ${ }^{3}$ (Table 1; showed by Stoffels and Kastner ${ }^{4}$ ).

Cite this article: Lotfy, R., Ali, O., Zarouk, W., El-Bassyouni, H., Nour El-Din, G. Epigenetics and Familial Mediterranean fever. Azhar International Journal of Pharmaceutical and Medical Sciences, 2021; 1(2):1-12. 
Table (1): Autoinflammatory disorders and evidence of epigenetic contribution to pathogeny

\begin{tabular}{|c|c|c|c|}
\hline Mutated gene & Disease & Effector cytokine & $\begin{array}{l}\text { Data on } \\
\text { epigenetic } \\
\text { regulation }\end{array}$ \\
\hline \multicolumn{4}{|c|}{ Hereditary monogenic periodic fever syndromes } \\
\hline MEFV & Familial Mediterranean Fever & IL-1 $\beta$ & $\mathrm{Yes}^{5}$ \\
\hline TNFRSF1A & TRAPS & IL-1 $\beta$ & No \\
\hline MVK & Hyper IgD syndrome & IL-1 $\beta$ & No \\
\hline NLRP3 & $\begin{array}{l}\text { Cryopyrin-associated periodic syndromes } \\
\text { [familial cold autoinflammatory syndrome } \\
\text { (FCAS), Muckle-Wells syndrome, } \\
\text { Neonatal-onset multisystem inflammatory } \\
\text { disease/CINCA] }\end{array}$ & IL-1 $\beta$ & Yes $^{6}$ \\
\hline NLRC4 & NLRC4-MAS & IL-1 $\beta / \mathrm{IL}-18$ & No \\
\hline PSTPIP1 & PAPA & IL-1 $\beta$ & No \\
\hline NLRP12 & FCAS2 & IL-1 $\beta$ & No \\
\hline \multicolumn{4}{|c|}{ Antagonist deficiencies } \\
\hline IL1RN & DIRA & IL-1 $\beta$ & No \\
\hline IL36RN & DITRA & IL-36 & No \\
\hline \multicolumn{4}{|c|}{ Complex autoinflammatory disorder } \\
\hline & Behçet & IL-6/IL-1 $\beta$ & Yes $^{7-9}$ \\
\hline & $\mathrm{CRO} /$ chronic recurrent multifocal osteomyelitis & IL-10/IL-1 $\beta$ & Yes $^{10,11}$ \\
\hline & Crohn & IL-19/IL-3/IL-27 & Yes $^{12,13}$ \\
\hline
\end{tabular}

Note: Data are from "Old dogs, new tricks: monogenic autoinflammatory disease unleashed." by Stoffels M, Kastner DL., 2016, Annual review of genomics and human genetics.;17:245-72. doi: 10.1146/annurev-genom-090413-025334

Thus, individual subjective issues regarding health and illness should remain doubtful. Amongmost patients, no test absolutely will determine the correct diagnosis. Cases sometimes require several tests that need an extended period, moreover the worry of meeting a practitioner ${ }^{14}$.

Epigenetics as sure providing modern thoughts to improve the clinical and diagnostic approaches in addition to eliminating the difference between environmental influences and hosting genetics. Epigenetics possesses the possibility of being utilized as a biomarker of illness identification and treatment, illness observation, as well as therapy reaction. Over the last years, pharmacogenetics has gained vast attention also epigenetic drug (epidrug) improvement has made considerable progress ${ }^{14}$.

\section{DEFINITION OF EPIGENETICS}

Epigenetics is a review of mitotic (and possibly meiotic) genetic modification in gene expressions due to variations within DNA series ${ }^{15}$. But other epigenetics' principles are profound even do not require hereditary. For example, the US National Institutes of Health (2009) stated through their final venture that epigenetics shows the two genetic differences within genes activity and expressions (through offspring of cells or persons) and steady, prolonged-term modifications in the cursive capacity concerning cell which are unnecessarily hereditary. Irrespective of the right definition, epigenetic mechanisms that steadily modify genes expressions types (and/or transport modifications in cell splitting) are believed to contain: DNA methylation, modulations of histone, chromatin remodeling and also the non-coding RNAs ${ }^{16}$.

\section{SIGNIFICANCE OF EPIGENETIC STUDY}

The detection and usage of epigenetic biomarkers own the possibility of affecting the treatment and clinical outcomes positively ${ }^{17}$. 
Biomarkers are linked to how the disease develops and even the final diagnosis. Some biomarkers could also be possible curative goals or show that seeking these aims should start 18, 19. Possible markers foundation is just the initial stage because those signs have to be proven and convinced like a credible and statistically accepted image of a certain disease. The epigenetic biomarkers were previously integrated into different clinical fields and are utilized in the prophylaxis, and management of malignancy, disorders of autoimmunity, in addition to neurological and cardiac problems ${ }^{14}$.

In fact, we can find many merits of epigenetic biomarkers. Firstly, those signs show a modern trend in which molecular characters relate to genic and environmental influences that develop diseases ${ }^{20}$.

Epigenetics supply useful biomarkers that do not rely on DNA series only. The epigenetic biomarkers, specifically those associated with DNA methylation, place out the DNA and RNA on the basis of checking sequences and may supply a different settlement profile ${ }^{17}$. Investigation of epigenetic biomarkers may be performed on samples from blood, tissue, body fluid, and excretions generally obtained during surgical operations ${ }^{14}$.

Moreover, the epigenetics disturbance may be tested within the genome context, before and even at the beginning of the disease in comparison with the RNA and protein-based testing in which abnormalities seem at comparatively delayed phases and sometimes in lower quantity or concentrations ${ }^{14}$.

\section{EPIGENETICS MECHANISMS}

\subsection{DNA Methylation and DNA hydroxymethylation}

Adding the methyl group onto the 5'carbon location of cytosine into

cytosine-phosphate-guanosine $(\mathrm{CpG})$ dinucleotides will significantly decrease DNA access for RNA polymerases transcription factors and, leading to suppression of transcription (Figure 1A). The DNA methyltransferase (DNMT) enzymes are accountable for keeping methylation. The DNA re-methylation is fundamental throughout cell split to transcribe the epigenetic code to the reproduction of the daughter cell. However, the de novo methylation to formerly functional genes' silence may contribute to the gene system's regulation. DNMT1 and DNMT2 are accountable for the re-methylation of DNA through the cell division ${ }^{21,22}$, while DNMT3a and 3b insert modern methyl categories into already unmethylated DNA $^{23}$.The condition is perhaps extracomplicated, and differentiation between conservation and $d e$ novo DNMTs is probably not justified or has an excessive simplification such as DNMT1 is actually implicated in the daughter strands methylation for and may be alternative to illness prognostic factors the duration of the cell division and the organizational areas' de novo methylation ${ }^{24}$.

DNA methylation may be modified via Ten-eleven transmit methylcytosine dioxygenase (TET) proteins that transform the methyl group to the hydroxymethylcytosines ${ }^{25}$. So, the DNA hydroxymethylation seemed to be a medium within the method of intense DNA methylation of the copied suppressed genes to a demethylated case in uncovered and copied actively chromatin ${ }^{26}$. Hydroxymethylated $\mathrm{CpG}$ positions are unaffected by DNMTs, thus from DNA methylation ${ }^{27}$. The lack of TET proteins and hence hydroxyl diversions suppression may lead to high DNA methylation standards. Therefore, hydroxymethylation seemed to be a separate steady epigenetic condition ${ }^{25}$. DNA hydroxymethylation sounds to be an active epigenetic condition ${ }^{25}$. DNA hydroxymethylation sound to be an active epigenetic sign and identifies with raised gene expressions in comparison with methylated DNA ${ }^{26}$ (Figure 1A).

\subsection{Histone modifications}

DNA is enfolded around histone protein groups, octamers including both transcribe of every histones $\mathrm{H} 2 \mathrm{~A}, \mathrm{H} 2 \mathrm{~B}, \mathrm{H} 3$, and the three dimensions that regulate its formation and access to the copied combination and H4. The histone proteins may be changed in their N-terminal amino deposits, which intermediates modifications through their electric ration and thereby determine the chromatin access to the copied combination ${ }^{29}$. A number of histone alterations were recorded, involving acetylation, methylation, or citrullination (Figure 1B). Instances for "silencing" histone changes contain H3K tri-methylation (H3K9me3), histone 3 lysine 9 di-methylation (H3K9me2), and even H3K27me3, while histone 4lysine 16 acetylation (H4K16ac), H3K4me3, H3K18ac, H3K27ac, and also H3K56ac seem to be activating reproduction signs ${ }^{30-33}$. As noted, histone alterations and $\mathrm{CpG}$ methylation are linked throughout methyl-CpG-binding proteins $(\mathrm{MBD})^{34}$. Those proteins induct two histone deacetylases and methyltransferases that lead to silencing throughout the alteration of histone ${ }^{34,35}$. Furthermore, histone tail alterations may let and even prevent the DNMT3linkage ${ }^{36}$.

\subsection{Non-coding RNAs}

The non-coding RNAs (ncRNA) seem to be active molecules of RNA but without translation into protein, also they are included in numerous biological procedures. According to nearly 1-2\% in the individual genome encoded a protein, we have had very little information about the remaining 
genome till current times. Besides that, the RNA world was sometimes dependent on outcomes of

A



B

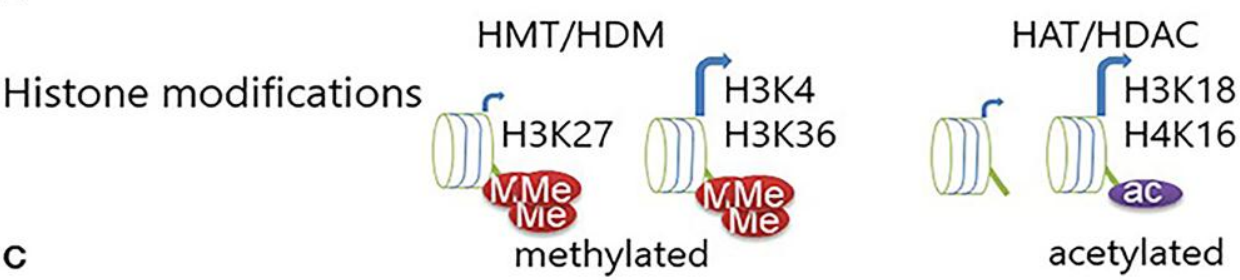

ncRNA



D

miRNA
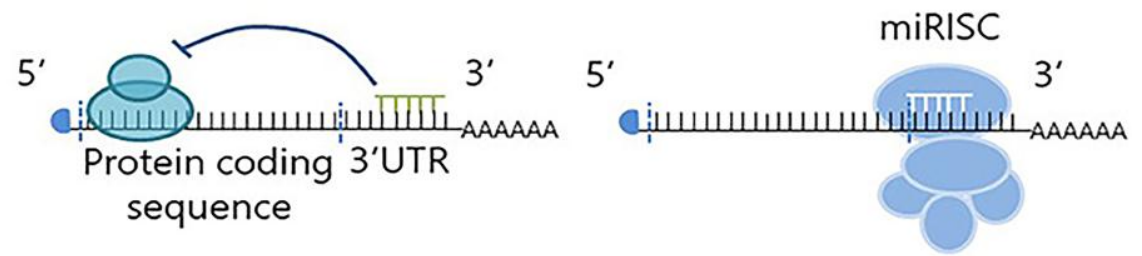

Figure 1: Epigenetics mechanisms. (A) DNA methyltransferase (DNMT) enzymes generate (de novo) DNA methylation at CpG dinucleotides. DNA Hydroxymethylation is achieved through oxidation of methylated CpG DNA and mediated by Ten-eleven translocation methylcytosine dioxygenase (TET) proteins. (B) Histone methyltransferases (HMT) can add (one to three) methyl groups to histone amino termini. (C) The transcription of non-coding RNA from intergenic or intronic regions can promote coding mRNA transcription by providing an open chromatin formation. (D) Short micro-RNAs (miRNA) can mediate transcriptional repression through inhibition of the ribosome when binding to the 3'UTR region of mRNAs. Also, miRNAs can stimulate the mRNA degradation through initiation of the miRISC complex ${ }^{28}$. Copyright note: From "The role of epigenetics in autoimmune/inflammatory disease," by Surace AE, Hedrich CM, 2019, Frontiers in immunology. 10:1525. (https://doi.org/10.3389/fimmu.2019.01525).

protein-coding mRNA research. Noncoding RNAs were assessed to be "evolutional junk RNAs"37, 38 . The RNA nature without coding is analyzed within two groups according to the numbers of nucleotides in the RNA molecule. The non-coding RNAs of up to 200 nucleotides are known as tiny or short ncRNA, while over 200 nucleotides are classified as long ncRNA. To the management of the nature of biological functions, ncRNAs are important. Worldwide, researchers are interested in identifying biological mechanisms or systems where the ncRNAs directly or indirectly operate through study for their roles. The non-coding RNA group (piwi-interacting RNA, small nucleolar RNAs, small interfering RNAs, microRNAs, circular RNAs, antisense RNAs, long intergenic non-codingRNA, in addition to other types) include various sections, however many studies throughout the literature are concentrated on miRNAs and long RNAs that not coded $^{37,39}$ (Figure 1C).

\subsection{MicroRNAs}

MicroRNAs (miRNAs) are small (ranging from 18 to 25 nucleotides), endogenous non-coding RNAs; they are efficient in the evolution and accountable for post reproduction organization of gene expressions ${ }^{40}$. It is suggested that most of the protein-encoding gene expressions in the individual genome are managed via 2654 ripe miRNAs (miRBase, http://www.mirbase.org) specified to date $^{41}$. The miRNAs may have many goals, while genes may be controlled with many miRNAs. Thus, miRNAs own significant impacts on eukaryotic organisms' cellular and developmental courses; miRNAs may have complete and even weak linkage to the $3^{\prime}$ translated area ( $3^{\prime}$ UTR) in target genes within the mature sequences of mRNA, instantly damaging mRNA or causing translation inhibition ${ }^{42}$. But, it is assumed that the 3' UTR areas well as the 5' UTR (near the cap site) is perhaps targeted by 
miRNAs, so contributing to miRNA-mediated post-transcription regulation ${ }^{43}$. In addition, several works have indicated that miRNAs may facilitate transcription genes activating (TGA). miRNA is included within genes activating via linking to the goal genes' mRNA and inducing a protein combination containing transcribed activators ${ }^{44,45}$ (Figure 1D).

Long non-coded RNAs (LncRNAs) are formed from two protein-encoding (e.g., H19 and TUG1) and DNA areas that are not coded. LncRNAs seem to be capable of regulating the gene expressions included in several cellular systems' regulation with their complicated structures ${ }^{46}$. Moreover, in contrast to miRNAs, LncRNAs may be poorly protected while comparing the nucleotide sequencing among species $^{47}$.

Long uncoded RNAs have proven strongly developed but differentiate within various forms of cells and tissues. Lately, a sum of 14,880 lncRNA transcripts was recorded via the GENCODE consortium gathered through the ENCODE venture, containing 9277 human origins generating from the gene's position 5362 LncRNAs, and 9518 intergenic LncRNAs (LincRNAs) ${ }^{48}$. The detection of LncRNAs has supplied an important development in the classification of RNA-based processes in controlling gene expressions. LncRNAs may organize the transcription function of a certain gene or a certain chromosomal area. The best-known case, Xist, a $17-\mathrm{kb} \mathrm{X}$-chromosome transcription, is the main controller of polycomb-suppressor complexes (PRC) to combine compound parts and initiate X-chromosome inhibition ${ }^{49}$. On the contrary, LncRNAs like MALAT1 and H19 are efficient within lipid and carbohydrate metabolism in addition to protein combination and dissolution 50 , 51

\section{EPIGENETICS AND GENE EXPRESSION}

Proteins transcription, translation, and sequent modulation are transmitted genetic data from the DNA copy from the archive to the short-lived RNA transporter, generally with sequent protein generation. Though each cell in the organism has basically the same DNA, cell kinds and roles are different due to discrepancies of quality and quantity in their gene expression. Subsequently, gene expression management is at the centre of uniqueness and evolution. Gene expression types that characterize distinguished cells are shaped throughout evolving and retained as cells divided by mitosis. Therefore as well as genetic material, cells gain material that is not encoded in the DNA nucleotide subsequence, which has been referred to as epigenetic information ${ }^{52}$.

\section{EPIGENETICS OF AUTO-INFLAMMATORY DISORDERS:}

Familial Mediterranean Fever is considered the commonest inherited autoinflammatory disorder (MIM \#249100). It's an autosomal recessive disorder that principally impacts individuals in the eastern Mediterranean basin and thus its name. The International FMF organization defined mutations causing the diseasein 1997. The mutations were found to occur in the MEFV genes on chromosome $16 \mathrm{p}^{53}$. MEFV encoding for pyrin, a significant complex of inflammasomes that interacting with caspase-1 and other inflammasome compounds to organize IL-1 $\beta$ generation ${ }^{54,55}$. Although the consistency of MEFV as the cause of FMF was for more than 20 years, pyrin function has been discussed. Previous research on mice demonstrated that pyrin prevents caspase-1, and the researchers recommended an anti-inflammatory function to pyrin $^{56}$. Different studies showed pyrin assembling an inflammasome compound and act as a pro-inflammatory ${ }^{57-59}$. Finally, it may be demonstrated that homozygous obtain-of-role pyrin mutation in mice causes pyrin inflammasome activation and acute inflammatory phenotypes via producing two pyrin-imperfect and knock-in mice that have mutated human B30.2 domains ${ }^{60}$. The system of pyrin inflammasome activity had been defined in 2016. It may be manifested that the pyrin inflammasome is organized through RhoA-dependent phosphorylation. Phosphorylated pyrin interacting with chaperone proteins 14-3-3 to keep pyrin dormant. Dysregulated interaction among 14-3-3 and pyrin results inactivation of pyrin inflammasome ${ }^{61,62}$. FMF is featured by abdominal and chest pain, frequent fever, in addition to arthritis $^{63}$. FMF diagnosis sometimes depends on the phenotypical Tel Hashomer ${ }^{64}$ or Yalcinkaya-Ozen standards ${ }^{65}$ and may be aided with genetic investigation $^{66}$. In $20 \%$ of cases with an FMF phenotype, a second mutation of the MEFV gene may not be observed ${ }^{67}$.

Familial Mediterranean Fever patients with identical genotypes can present various phenotypes of the disease. This disparity could be because of other altering genes, epigenetics, or environmental influences. The first hint of the environmental effects on FMF was the discovery of the absence of minor amyloidosis amongst Armenian FMF cases in the $\mathrm{USA}^{68}$. In case of moving to Europe, the eastern Mediterranean patients are known to have a less dangerous disease ${ }^{69}$.The environmental influences might affect the presence of different phenotypes among FMF patients. One of these factors might be the living country ${ }^{70,71}$. They may be based on genetic factors coupled with a region of specific influences such as nutritional patterns, privation, working environments, as well as environmental matrice 
pollution. These findings are important, particularly to the assessment of the human capability of amyloidosis $^{71}$. A previous study of FMF cases from 14 communities found that the residence state was the key factor evaluating the elevated risk of amyloidosis rather than the MEFV genotype ${ }^{71}$. In addition, a contrast among Turkish kids who have FMF staying in Turkey or Germany revealed a higher extreme disease trend for those in Turkey, showing the climate as a clear influencer of the FMF phenotype $^{70}$.

Additionally, previous studies comparing cases with identical history staying in Turkey or Germany have enabled environmental impact assessment of FMF intensity, where variables of the environment can cause over $12 \%$ of phenotypic variance ${ }^{72,73}$. Besides, advances in DNA methylation of the MEFV reasoned FMF genes were reported to minimize MEFV expressions through FMF environmental leukocytes in 51 FMF cases relative to 21 healthy regulations. These results underscore the environmental effects on serious FMF disease ${ }^{5,74}$.

\section{EPIGENETICS AND MICROBIOTA}

Although FMF seems to be a monogenic disease, epigenetic influences as well as microbiota could perform a function in the FMF pathogenesis or phenotypic expressions. It is enticing to estimate that interactions of host-microbe could be significant to this inherent immune system disease. Khachatryan et al. have shown that microbiota's structure and ramification varied through cycles with and without attack, also between FMF cases and healthy controls $^{75}$. Microorganisms can influence FMF because pyrin is an NLRP3 component that is a receptor for pathogen recognition ${ }^{69}$. It has been demonstrated that pyrin reveals virulent pathogenic activity. Cross taking of the inherent immune system and commensal gut bacteria (microbiota) also could influence (or could be influenced by) the case inflammatory state. Microbiota composition and divergence varied through the attack and attack-free times also between FMF cases and stable controls ${ }^{69}$.

Throughout that case, impacts of the environment influencing the gut microbiota may play apart in defining the start and intensity of disorders of the innate inflammatory pathway in the sense of a monogenic disease. Gut microbiota can also be a cause for the initiation of AA amyloidosis, which is one of the morbidity factors in FMF patients $^{76}$. However, dependent on the MEFV genotype, various standards of basic status activating of pyrin could likely affect the intestinal homeostasis in the gut giving a complex inter-individual risk of developing chronic inflammation. Microbiota metabolites are able to modulate other inflammasomes under this light ${ }^{77}$. In the host gut, the microbiota plays an important role and is vulnerable to variants of genes and environment, either in health or disease. Being a type of uncommon hereditary autoinflammatory monogenic disease, FMF presents a history of intermittent inflammatory variants, having a significant effect on innate immunity. The microbiota is particularly susceptible to these inflammatory variants. Additionally, unique autoinflammatory reactions in FMF can be controlled. FMF symptoms can also be susceptible, and this emerging problem needs further consideration as an environmental, genetic interactivity model. Gut microbiota is potentially a crucial element in the determination of the FMF phenotype. Plenty of microbiota and its form in FMF cases can be based on genetic and environmental factors, though it has a secondary function.In contrast, environmental factors may be crucial in the long run in shaping the nature of the condition and the symptoms onset (i.e., AA amyloidosis). In FMF patients, future research should investigate gene-environment interactions. In addition, potential beneficial effects resulting from external gut microbiota modulation need further research into how complex probiotic therapies could enhance symptoms and development of microbiota without affecting the valuable impacts of the main curative choice in cases with $\mathrm{FMF}^{78}$. Growing proof is accumulating the function of intestinal microbiota in bile acid bioconversion within inter-individual differences leading predisposition to infection, converted metabolism and immune reaction. So, the genetic factors can be one of the factors deciding the intestinal microbiota profile in subjects with $\mathrm{FMF}^{79}$, 80.

\section{SUMMARY AND CONCLUSIONS}

Epigenetics perform an unbiased but essential function in autoimmune/inflammatory pathophysiology disorders. Histone alterations, non-coding RNAs, and also the CpG DNA methylation, are the greatest proofs. However, we recently just begin understanding this and the processes by which epigenetic activities cause disease. Full interpretation of epigenetic disease aetiologyis difficult as epigenetic conditions are highly complicated and occur accompanied by other epigenetic signs. They are unsteady and rely on several changes, containing cell cycle and exterior influences involving the immunologic micro-environment. A number of epigenetic alterations, implied reasons, and their participation in the pathophysiology has been approved, and otherchanges can cause a minor condition in regularity autoimmune/inflammatory illness and outstanding inflammation. 
Nevertheless, secondary epigenetic changes could affect inflammatory reactions, and their curative target may further regulate inflammation and tissue spoil. But, aside from cancer therapy, "epigenetic therapies "recentlystill" science fiction" in the immunology and rheumatology domain, as aim-directed implementation is recently unavailable. Epigenetic alterations are complicated, as well as not targeted methods are related to genome-wide modifications, which can cause severe side-effects, even worsening the disease. Therefore, current studies are justified in offering a further detailed view of epigenetic causes of inflammation and unregulated immune, and their fundamental molecular reasons.

Just one complete image of epigenetics in the systemic inflammation will aid in:

(i) Understanding the r typical
autoimmune/inflammatory
pathophysiology.

(ii) Delivering molecular contributors for changeable manifestations, disease intensity, and results within associated individuals who have the phenotypically changing illness, and (iii) offering other goals into the study for vital signs in addition to individual and target-directed therapies.

Conflict of interest: All authors declared no conflict of interest.

Author contribution: All authors contributed significantly in writing, revising and editing the manuscript.

Funding: There is no any funding source for this study.

\section{List of Abbreviations:}

CAPS : cryopyrin-associated periodic syndromes

DNMT: DNA methyltransferase

FCAS2: Familial cold autoinflammatory syndrome-2

FMF : Familial Mediterranean fever

H3K27me3: histone 3 lysine 9 tri-methylation

H3K9me2: histone 3 lysine 9 di-methylation

H3K9me3: H3K tri-methylation

H4K16ac : histone 4lysine 16 acetylation

LincRNAs : intergenic LncRNAs

LncRNAs : Long non-coded RNAs

MBD: methyl-CpG-binding proteins

MEFV : Mediterranean Fever

MicroRNAs (miRNAs)

mRNA: messenger RNA

MVK : Mevalonate Kinase

ncRNA : non-coding RNAs

NLRC4 : NLR Family CARD Domain Containing 4

NLRC4-MAS:NLRC4-Related Macrophage

Activation Syndrome

NLRP12: NACHT, LRR and PYD

domains-containing protein 12

NLRP3 : NOD-, LRR- and pyrin domain-containing protein 3
PAPA syndrome: Pyogenic Arthritis, Pyoderma gangrenosum and Acne

PRC : polycomb-suppressor complexes

PSTPIP1: Proline-Serine-Threonine Phosphatase Interacting Protein 1

TET: Ten-eleven transmit methylcytosine dioxygenase

TNFRSF1A : TNF Receptor Superfamily Member $1 \mathrm{~A}$

TRAPS: Tumor necrosis factor receptor-associated periodic syndrome

\section{REFERENCES}

1. Canna SW, Goldbach-Mansky R. New monogenic autoinflammatory diseases - a clinical overview. Seminars in Immunopathology. 2015;37(4):387-94. doi:10.1007/s00281-015-0493-5

2. Masters SL, Anna Simon, Ivona Aksentijevich, Kastner DL. Horror Autoinflammaticus: The molecular pathophysiology of autoinflammatory disease. Annual review of immunology. 2009;27(1):621-68.

doi:10.1146/annurev.immunol.25.022106.1 41627

3. Álvarez-Errico D, Vento-Tormo R, Ballestar E. Genetic and epigenetic determinants in autoinflammatory diseases. Frontiers in immunology. 2017;8(318). doi:10.3389/fimmu.2017.00318

4. Stoffels M, Kastner DL. Old dogs, new tricks: monogenic autoinflammatory disease unleashed. Annual review of genomics and human genetics. 2016;17:245-72. doi: 10.1146/annurev-genom-090413-0253 34

5. Kirectepe AK, Kasapcopur O, Arisoy N, Celikyapi Erdem G, Hatemi G, Ozdogan H, et al. Analysis of MEFV exon methylation and expression patterns in familial Mediterranean fever. BMC Medical Genetics. 2011;12(1):105 doi:10.1186/1471-2350-12-105

6. Vento-Tormo R, Álvarez-Errico D, Garcia-Gomez A, Hernández-Rodríguez J, Buján S, Basagaña $\mathrm{M}$, et al. DNA demethylation of inflammasome-associated genes is enhanced in patients with cryopyrin-associated periodic syndromes. Journal of allergy and clinical immunology. 
2017;139(1):202-11.e6. doi:10.1016/j.jaci.2016.05.016

7. Hughes T, Ture-Ozdemir F, Alibaz-Oner F, Coit P, Direskeneli H, Sawalha AH. Epigenome-wide scan identifies a treatment-responsive pattern of altered DNA methylation among cytoskeletal remodeling genes in monocytes and CD4+ T cells from patients with Behçet's disease. Arthritis \& Rheumatology. 2014;66(6):1648-58.

doi: /10.1002/art.38409

8. Zhou Q, Xiao X, Wang C, Zhang X, Li F, Zhou Y, et al. Decreased microRNA-155 expression in ocular Behcet's disease but not in Vogt Koyanagi Harada Syndrome. Investigative ophthalmology \& visual science. 2012;53(9):5665-74.

doi:10.1167/iovs.12-9832

9. Qi J, Yang Y, Hou S, Qiao Y, Wang Q, Yu $\mathrm{H}$, et al. Increased Notch pathway activation in Behçet's disease. Rheumatology. 2014;53(5):810-20.

doi:10.1093/rheumatology/ket438

10. Hofmann SR, Schwarz T, Möller JC, Morbach H, Schnabel A, Rösen-Wolff A, et al. Chronic non-bacterial osteomyelitis is associated with impaired Sp1 signaling, reduced IL10 promoter phosphorylation, and reduced myeloid IL-10 expression. Clinical Immunology. 2011;141(3):317-27. doi: 10.1016/j.clim.2011.08.012

11. Hofmann SR, Kubasch AS, Ioannidis C, Rösen-Wolff A, Girschick HJ, Morbach H, et al. Altered expression of IL-10 family cytokines in monocytes from CRMO patients result in enhanced IL- $1 \beta$ expression and release. Clinical Immunology. 2015;161(2):300-7. doi:10.1016/j.clim.2015.09.013

12. Lin Z, Hegarty J, Cappel J, Yu W, Chen X, Faber $P$, et al. Identification of disease-associated DNA methylation in intestinal tissues from patients with inflammatory bowel disease. Clinical Genetics. 2011;80(1):59-67. doi:10.1111/j.1399-0004.2010.01546.x

13. Harris RA, Nagy-Szakal D, Mir SAV, Frank E, Szigeti R, Kaplan JL, et al. DNA methylation-associated colonic mucosal immune and defense responses in treatment-naïve pediatric ulcerative colitis. Epigenetics. 2014;9(8):1131-7. doi:10.4161/epi.29446

14. Zhang L, Lu Q, Chang C. Epigenetics in Health and Disease. In: Chang C, Lu Q, editors. Epigenetics in allergy and autoimmunity. Singapore: Springer Singapore; 2020. p. 3-55.

15. Waterland RA. Epigenetic mechanisms and gastrointestinal development. The Journal of pediatrics. 2006;149(5):S137-S42. doi:10.1016/j.jpeds.2006.06.064

16. Álvarez-Errico D, Vento-Tormo R, Sieweke M, Ballestar E. Epigenetic control of myeloid cell differentiation, identity and function. Nature reviews immunology. 2015;15(1):7-17. doi:10.1038/nri3777

17. García-Giménez JL, Seco-Cervera M, Tollefsbol TO, Romá-Mateo C, Peiró-Chova L, Lapunzina $\mathrm{P}$, et al. Epigenetic biomarkers: Current strategies and future challenges for their use in the clinical laboratory. Critical reviews in clinical laboratory sciences. 2017;54(7-8):529-50. doi:10.1080/10408363.2017.1410520

18. Costa-Pinheiro P, Montezuma D, Henrique $\mathrm{R}$, Jerónimo C. Diagnostic and prognostic epigenetic biomarkers in cancer. Epigenomics. 2015;7(6):1003-15. doi:10.2217/epi.15.56

19. Dirks RAM, Stunnenberg HG, Marks H. Genome-wide epigenomic profiling for biomarker discovery. Clinical epigenetics. 2016;8(1):122.

doi:10.1186/s13148-016-0284-4

20. Lorincz AT. The promise and the problems of epigenetic biomarkers in cancer. Expert Opinion on medical diagnostics. 2011;5(5):375-9. doi:10.1517/17530059.2011.590129

21. Kaiser S, Jurkowski TP, Kellner S, Schneider D, Jeltsch A, Helm M. The RNA methyltransferase DNMT2 methylates DNA in the structural context of a tRNA. RNA Biology. 2017;14(9):1241-51. doi: $10.1080 / 15476286.2016 .1236170$ 
22. Rountree MR, Bachman KE, Baylin SB. DNMT1 binds HDAC2 and a new co-repressor, DMAP1, to form a complex at replication foci. Nature Genetics. 2000;25(3):269-77. doi:10.1038/77023

23. Bachman KE, Rountree MR, Baylin SB. DNMT3a and DNMt3b are transcriptional repressors that exhibit unique localization properties to heterochromatin*. Journal of biological 2001;276(34):32282-7. doi:10.1074/jbc.M104661200

24. Hedrich CM, Mäbert K, Rauen T, Tsokos GC. DNA methylation in systemic lupus erythematosus. 2016;9(4):505-25. doi:10.2217/epi-2016-0096

25. Huang Y, Chavez L, Chang X, Wang X, Pastor WA, Kang J, et al. Distinct roles of the methylcytosine oxidases Tet1 and Tet2 in mouse embryonic stem cells. Proceedings of the National Academy of Sciences. 2014;111(4):1361-6. doi. 10.1073/pnas.1322921111

26. Hackett JA, Sengupta R, Zylicz JJ, Murakami K, Lee C, Down TA, et al. Germline DNA demethylation dynamics and imprint erasure through 5-hydroxymethylcytosine. Science. 2013;339(6118):448-52. doi:10.1126/science.1229277

27. Valinluck V, Sowers LC. Endogenous cytosine damage products alter the site selectivity of human DNA maintenance methyltransferase DNMT1. Cancer research. 2007;67(3):946-50. doi: 10.1158/0008-5472.can-06-3123

28. Surace AE, Hedrich CM. The role of epigenetics in autoimmune/inflammatory disease. Frontiers in immunology. 2019;10:1525. doi: 10.3389/fimmu.2019.01525

29. Hedrich CM, Tsokos GC. Epigenetic mechanisms in systemic lupus erythematosus and other autoimmune diseases. Trends in molecular medicine. 2011;17(12):714-24. doi:10.1016/j.molmed.2011.07.005

30. Hedrich CM, Mäbert K, Rauen T, Tsokos GC. DNA methylation in systemic lupus erythematosus. Epigenomics. 2017;9(4):505-25. doi:10.2217/epi-2016-0096

31. Hedrich CM, Rauen T, Tsokos GC. cAMP-responsive Element Modulator $(\mathrm{CREM}) \alpha$ protein signaling mediates epigenetic remodeling of the human interleukin-2 gene: Implications in systemic lupus erythematosus*. Journal of biological chemistry. $\quad 2011 ; 286(50): 43429-36$. doi:10.1074/jbc.M111.299339

32. Heintzman ND, Stuart RK, Hon G, Fu Y, Ching CW, Hawkins RD, et al. Distinct and predictive chromatin signatures of transcriptional promoters and enhancers in the human genome. Nature Genetics. 2007;39(3):311-8. doi:10.1038/ng1966

33. Peeters JGC, Picavet LW, Coenen SGJM, Mauthe M, Vervoort SJ, Mocholi E, et al. Transcriptional and epigenetic profiling of nutrient-deprived cells to identify novel regulators of autophagy. Autophagy. 2019;15(1):98-112.doi:10.1080/15548627.2 018.1509608

34. Nan X, Ng H-H, Johnson CA, Laherty CD, Turner BM, Eisenman RN, et al. Transcriptional repression by the methyl-CpG-binding protein MeCP2 involves a histone deacetylase complex. Nature. 1998;393(6683):386-9. doi:10.1038/30764

35. Fuks F, Hurd PJ, Wolf D, Nan X, Bird AP, Kouzarides T. The Methyl-CpG-binding Protein MeCP2 links dna methylation to histone methylation*. Journal of biological chemistry. 2003;278(6):4035-40 doi:10.1074/jbc.M210256200

36. Zhang Y, Jurkowska R, Soeroes S, Rajavelu A, Dhayalan A, Bock I, et al. Chromatin methylation activity of DNMT3a and DNMT3a/3L is guided by interaction of the ADD domain with the histone $\mathrm{H} 3$ tail. Nucleic acids research. 2010;38(13):4246-53. doi:10.1093/nar/gkq147

37. Pea A, Jamieson NB, Braconi C. Biology and clinical application of regulatory rnas in hepatocellular carcinoma. hepatology. 2021;73(S1):38-48. doi:10.1002/hep.31225 
38. Zhang M, Huang N, Yang X, Luo J, Yan S, Xiao F, et al. A novel protein encoded by the circular form of the SHPRH gene suppresses glioma tumorigenesis. Oncogene. 2018;37(13):1805-14. doi:10.1038/s41388-017-0019-9

39. Hombach S, Kretz M. Non-coding RNAs: classification, biology and functioning. In: Slaby O, Calin GA, editors. Non-coding RNAs in Colorectal cancer. Cham: Springer International Publishing; 2016. p. 3-17.doi: 10.1007/978-3-319-42059-2_1

40. MacFarlane L-A, R. Murphy P. MicroRNA: Biogenesis, Function and Role in Cancer. Current Genomics. 2010;11(7):537-61. doi:10.2174/138920210793175895

41. Kozomara A, Birgaoanu M, Griffiths-Jones S. miRBase: from microRNA sequences to function. Nucleic Acids Research. 2018;47(D1):D155-D62. doi:10.1093/nar/gky1141

42. Xiao X, Wu Z-C, Chou K-C. A multi-label classifier for predicting the subcellular localization of gram-negative bacterial proteins with both single and multiple sites. PloS one. 2011;6(6):e20592. doi: 10.1371/journal.pone.0020592

43. Warf MB, Berglund JA. MBNL binds similar RNA structures in the CUG repeats of myotonic dystrophy and its pre-mRNA substrate cardiac troponin T. RNA. 2007;13(12):2238-51.doi: 10.1261/rna.610607

44. Vasudevan S. Posttranscriptional upregulation by microRNAs. Wiley Interdisciplinary Reviews: RNA 2012;3(3):311-30. doi: 10.1002/wrna.121

45. Huang HY, Lin YC, Li J, Huang KY, Shrestha S, Hong HC, et al. miRTarBase 2020: updates to the experimentally validated microRNA-target interaction database. Nucleic Acids Res. 2020;48(D1):D148-d54.doi:10.1093/nar/gk z896

46. Yao R-W, Wang Y, Chen L-L. Cellular functions of long noncoding RNAs. Nature cell biology. 2019;21(5):542-51.doi: $10.1038 / \mathrm{s} 41556-019-0311-8$
47. Bininda-Emonds ORP, Cardillo M, Jones KE, MacPhee RDE, Beck RMD, Grenyer R, et al. The delayed rise of present-day mammals. Nature. 2007;446(7135):507-12. doi:0.1038/nature 05634

48. Cabili MN, Trapnell C, Goff L, Koziol M, Tazon-Vega B, Regev A, et al. Integrative annotation of human large intergenic noncoding RNAs reveals global properties and specific subclasses. Genes \& development. 2011;25(18):1915-27. doi: 10.1101/gad.17446611.

49. Brockdorff N, Ashworth A, Kay GF, McCabe VM, Norris DP, Cooper PJ, et al. The product of the mouse Xist gene is a 15 $\mathrm{kb}$ inactive $\mathrm{X}$-specific transcript containing no conserved ORF and located in the nucleus. Cell. 1992;71(3):515-26. doi:10.1016/0092-8674(92)90519-I

50. Ji P, Diederichs $\mathrm{S}$, Wang $\mathrm{W}$, Böing $\mathrm{S}$, Metzger R, Schneider PM, et al. MALAT-1, a novel noncoding RNA, and thymosin $\beta 4$ predict metastasis and survival in early-stage non-small cell lung cancer. Oncogene. 2003;22(39):8031-41. doi: 10.1038/sj.onc. 1206928

51. Brannan CI, Dees EC, Ingram RS, Tilghman SM. The product of the H19 gene may function as an RNA. Molecular and Cellular Biology.

1990;10(1):28-36.doi:10.1128/mcb.10.1.28

52. Gibney E, Nolan C. Epigenetics and gene expression. Heredity (Edinb) 2010; 105: 4-13. 2010.doi: 10.1038/hdy.2010.54

53. The International Fmf Consortium. Ancient missense mutations in a new member of the RoRet gene family are likely to cause familial Mediterranean fever. The International FMF Consortium. Cell. 1997;90(4):797-807.doi:10.1016/s0092-867 4(00)80539-5

54. de Torre-Minguela C, Mesa del Castillo P, Pelegrín P. The NLRP3 and pyrin inflammasomes: implications in the pathophysiology of autoinflammatory diseases. Frontiers in immunology. 2017;8(43). doi:10.3389/fimmu.2017.00043

55. Alghamdi M. Familial Mediterranean fever, review of the literature. Clinical 
Rheumatology. 2017;36(8):1707-13. doi:10.1007/s10067-017-3715-5

56. Papin S, Cuenin S, Agostini L, Martinon F, Werner S, Beer HD, et al. The SPRY domain of Pyrin, mutated in familial Mediterranean fever patients, interacts with inflammasome components and inhibits proIL-1 $\beta$ processing. Cell Death \& Differentiation. 2007;14(8):1457-66.

doi:10.1038/sj.cdd.4402142

57. Chae JJ, Wood G, Masters SL, Richard K, Park G, Smith BJ, et al. The B30.2 domain of pyrin, the familial Mediterranean fever protein, interacts directly with caspase- 1 to modulate IL-1 $\beta$ production. Proceedings of the National Academy of Sciences. 2006;103(26):9982-7. doi:10.1073/pnas.0602081103

58. Yu JW, Wu J, Zhang Z, Datta P, Ibrahimi I, Taniguchi $S$, et al. Cryopyrin and pyrin activate caspase-1, but not NF-kappaB, via ASC oligomerization. Cell death and differentiation. 2006;13(2):236-49. doi:10.1038/sj.cdd.4401734

59. Krainer J, Siebenhandl S, Weinhäusel A. Systemic autoinflammatory diseases. Journal of autoimmunity. 2020;109:102421. doi:10.1016/j.jaut.2020.102421

60. Chae Jae J, Cho Y-H, Lee G-S, Cheng J, Liu PP, Feigenbaum L, et al. Gain-of-function pyrin mutations induce NLRP3 protein-independent interleukin-1 $\beta$ activation and severe autoinflammation in mice. immunity. 2011;34(5):755-68. doi:10.1016/j.immuni.2011.02.020

61. Gao W, Yang J, Liu W, Wang Y, Shao F. Site-specific phosphorylation and microtubule dynamics control Pyrin inflammasome activation. Proceedings of the National Academy of Sciences. 2016;113(33):E4857-E66. doi:10.1073/pnas.1601700113

62. Park YH, Wood G, Kastner DL, Chae JJ. Pyrin inflammasome activation and RhoA signaling in the autoinflammatory diseases FMF and HIDS. Nature immunology. 2016;17(8):914.

doi: 10.1038/ni.3457
63. Sönmezgöz E, Özer S, Gül A, Yılmaz R, Kasap T, Takc1 Ş, et al. Clinical and demographic evaluation according to MEFV genes in patients with Familial Mediterranean Fever. Biochemical Genetics. 2019;57(2):289-300. doi:10.1007/s10528-018-9889-y

64. Livneh A, Langevitz P, Zemer D, Zaks N, Kees S, Lidar T, et al. Criteria for the diagnosis of familial mediterranean fever. Arthritis \& Rheumatism. 1997;40(10):1879-85. doi:10.1002/art.1780401023

65. Yalçınkaya F, Özen S, Özçakar ZB, Aktay N, Çakar N, Düzova A, et al. A new set of criteria for the diagnosis of familial Mediterranean fever in childhood. Rheumatology. 2009;48(4):395-8. doi:10.1093/rheumatology/ken509

66. Berkun Y, Eisenstein EM. Diagnostic criteria of familial Mediterranean fever. Autoimmunity reviews. 2014;13(4-5):388-90. doi: 10.1016/j.autrev.2014.01.045

67. Ozen S, Bilginer Y. A clinical guide to autoinflammatory diseases: familial Mediterranean fever and next-of-kin. Nature Reviews Rheumatology. 2014;10(3):135. doi: 10.1038/nrrheum.2013.174

68. Schwabe AD, Peters RS. Familial Mediterranean Fever in Armenians. Analysis of 100 cases. Medicine. 1974;53(6):453-62. doi: 10.1097/00005792-197411000-00005

69. Ozen S, Batu ED, editors. The myths we believed in familial Mediterranean fever: what have we learned in the past years? Seminars in immunopathology; 2015: Springer.doi: 10.1007/s00281-015-0484-6

70. Özen S. Changing concepts in familial mediterranean fever: Is it possible to have an autosomal-recessive disease with only one mutation? Arthritis \& Rheumatism. 2009;60(6):1575-7. doi:10.1002/art.24565

71. Touitou I, Sarkisian T, Medlej-Hashim M, Tunca M, Livneh A, Cattan D, et al. Country as the primary risk factor for renal amyloidosis in familial mediterranean fever. 
Arthritis \& Rheumatism. 2007;56(5):1706-12. doi:10.1002/art.22507

72. Ben-Zvi I, Brandt B, Berkun Y, Lidar M, Livneh A. The relative contribution of environmental and genetic factors to phenotypic variation in familial Mediterranean fever (FMF). Gene. 2012;491(2):260-3.

doi:10.1016/j.gene.2011.10.005

73. Giese A, Kurucay M, Kilic L, Örnek A, Şendur SN, Lainka E, et al. Quality of life in adult patients with Familial Mediterranean fever living in Germany or Turkey compared to healthy subjects: a study evaluating the effect of disease severity and country of residence. Rheumatology international. 2013;33(7):1713-9.doi:10.1007/s00296-012 $-2622-y$

74. Dogan E, Gursoy S, Bozkaya G, Camlar S, Kilicarslan O, Soylu A, et al. The effects of epigenetic regulation on phenotypic expressivity in Turkish patients with familial Mediterranean fever. Indian Journal of Rheumatology. 2019;14(4):297-303. doi:10.4103/injr.injr_24_19

75. Khachatryan ZA, Ktsoyan ZA, Manukyan GP, Kelly D, Ghazaryan KA, Aminov RI. Predominant role of host genetics in controlling the composition of gut microbiota. PloS one. 2008;3(8):e3064. doi:10.1371/journal.pone.0003064

76. Deshayes S, Fellahi S, Bastard J-P, Launay J-M, Callebert J, Fraisse T, et al. Specific changes in faecal microbiota are associated with familial Mediterranean fever. Annals of the rheumatic diseases. 2019;78(10):1398-404.

doi:10.1136/annrheumdis-2019-215258

77. Levy M, Thaiss Christoph A, Zeevi D, Dohnalová L, Zilberman-Schapira G, Mahdi Jemal A, et al. Microbiota-modulated metabolites shape the intestinal microenvironment by regulating NLRP6 inflammasome signaling. Cell. 2015;163(6):1428-43. doi:10.1016/j.cell.2015.10.048

78. Di Ciaula A, Stella A, Bonfrate L, Wang DQ, Portincasa P. Gut microbiota between environment and genetic background in Familial Mediterranean Fever (FMF).
Genes. 2020;11(9):1041. doi: 10.3390/genes11091041

79. Song X, Sun X, Oh SF, Wu M, Zhang Y, Zheng $\mathrm{W}$, et al. Microbial bile acid metabolites modulate gut $\mathrm{ROR} \gamma+$ regulatory $\mathrm{T}$ cell homeostasis. Nature. 2020;577(7790):410-5. doi:10.1038/s41586-019-1865-0

80. Theriot CM, Petri WA. Role of microbiota-derived bile acids in enteric infections. Cell. 2020;181(7):1452-4. doi.org/10.1016/j.cell.2020.05.033 